Etnográfica

Revista do Centro em Rede de Investigação em

Antropologia

vol. $23(3)$ | 2019

Vol. 23 (3)

\title{
Nação e integração nas escolas de fronteira: a mobilidade docente e a aprendizagem das línguas nacionais entre o Brasil e a Argentina
}

Nation and integration in schools at the borders: the mobility of teachers and the learning of national languages between Brazil and Argentina

Flávia Alves de Sousa e José Lindomar C. Albuquerque

\section{CpenEdition}

\section{Journals}

\section{Edição electrónica}

URL: https://journals.openedition.org/etnografica/7313

DOI: 10.4000/etnografica.7313

ISSN: 2182-2891

\section{Editora}

Centro em Rede de Investigação em Antropologia

Edição impressa

Data de publição: 1 outubro 2019

Paginação: 627-648

ISSN: 0873-6561

Refêrencia eletrónica

Flávia Alves de Sousa e José Lindomar C. Albuquerque, «Nação e integração nas escolas de fronteira: a mobilidade docente e a aprendizagem das línguas nacionais entre o Brasil e a Argentina»,

Etnográfica [Online], vol. 23 (3) | 2019, posto online no dia 28 novembro 2019, consultado o 21 janeiro 2022. URL: http://journals.openedition.org/etnografica/7313 ; DOI: https://doi.org/10.4000/

etnografica.7313

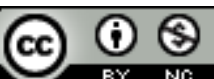

Etnográfica is licensed under a Creative Commons Attribution-NonCommercial 4.0 International License. 


\section{Nação e integração nas escolas de fronteira: a mobilidade docente e a aprendizagem das línguas nacionais entre o Brasil e a Argentina}

Flávia Alves de Sousa

e José Lindomar C. Albuquerque

As escolas nas zonas de fronteiras internacionais se constituem em um campo privilegiado para pensar as mobilidades transfronteiriças e a produção da nação no espaço escolar. O objetivo do artigo é pensar a circulação e a prática educativa de professoras argentinas e brasileiras entre duas escolas das cidades de Foz do Iguaçu (Brasil) e Puerto Iguazú (Argentina) que participam do Programa Escolas Interculturais de Fronteira (PEIF). Analisamos o processo de produção de fronteiras políticas, culturais e simbólicas a partir da percepção de diretoras, coordenadoras, professoras e alunos, tentando compreender os caminhos e os paradoxos dos dispositivos de integração educacional nas zonas fronteiriças internacionais no contexto do Mercosul.

PALAVRAS-CHAVE: fronteira, nação, integração, mobilidade, escola, língua.

Nation and integration in schools at the borders: the mobility of teachers and the learning of national languages between Brazil and Argentina - Schools at the borders are a privileged field for the study of cross-border mobilities and the production of the nation in the school space. The article's purpose is to reflect on the circulation and educational practice of Argentine and Brazilian teachers between two schools located at the frontier cities of Foz do Iguaçu (Brazil) and Puerto Iguazú (Argentina) that are included in the Intercultural Schools at the Borders Program (PEIF, in its Portuguese acronym). We analyze the process of production of political, cultural and symbolic boundaries as perceived by directors, coordinators, teachers and students, in an effort to understand the ways and the paradoxes arising out of the educational integration mechanisms in international borderland areas in the context of Mercosur (Common Market of the Southern Cone).

KEYWORDS: border, nation, integration, mobility, school, language.

SOUSA, Flávia Alves de (viasousa75@gmail.com) - Faculdade de Formação de Professores, Universidade do Estado do Rio de Janeiro (UERJ), Brasil.

ALBUQUERQUE, José Lindomar C. (joselindomar74@gmail.com) - Universidade Federal de São Paulo (Unifesp), Brasil. 


\section{INTRODUÇÃO}

A instituição escolar tem tido uma contribuição importante na produção e reprodução da identidade nacional nos dois últimos séculos (Bauer 2000; Billig 1998). Nesse espaço educacional, crianças e jovens aprendem os significados dos símbolos, narrativas, imagens e rituais nacionais. Sabemos que outras formas de pertencimento étnico, regional e local também são construídas atualmente em espaços escolares heterogêneos em contextos de implementação de políticas multiculturais. Entretanto, a forma hegemônica de imaginação escolar ainda é rotineiramente a de produzir a nação. Há um nacionalismo banal (Billig 1995), como prática repetitiva, construído no ambiente educacional: a bandeira nacional no pátio ou na biblioteca, o mapa do país em sala de aula ou na secretaria da escola, o calendário nacional, os símbolos e narrativas da pátria nos livros didáticos, etc.

Em relação às escolas situadas em áreas de fronteira internacional, elas se constituem em uma espécie de trincheira cultural (Castells 2001) do Estado-nação, particularmente em contextos históricos de afirmação do nacionalismo. Os professores geralmente são vistos como missionários da nação e responsáveis por "nacionalizar as crianças", combatendo, no cotidiano educacional, as palavras estrangeiras e misturadas advindas da influência da nação vizinha. As escolas nas zonas fronteiriças entre o Brasil e a Argentina tentaram cumprir, até mais ou menos a década de 1980, o objetivo predominante de nacionalizar a fronteira. Na região fronteiriça do Brasil, as instituições escolares foram concebidas como freios à presença estrangeira, sobretudo nos contextos do governo de Getúlio Vargas (1930-1945) e da Ditadura Militar (1964-1985). Na Argentina, as escolas próximas aos rios Uruguai e Paraná funcionaram respectivamente como uma defesa da fronteira contra o "intruso brasileiro" e a "fala paraguaia”, especialmente durante a Ditadura argentina (1976-1983). Era preciso argentinizar todo o território nacional. ${ }^{1}$

A escola como barreira cultural cede espaço para novas experiências de intercâmbios e mobilidades transfronteiriças de docentes e discentes em períodos mais recentes de integração regional. No âmbito do Mercado Comum do Cone Sul (Mercosul), nas duas primeiras décadas do século XXI, algumas medidas facilitaram os fluxos de estudantes e professores nas zonas de fronteira dos

l Na Argentina foram criadas várias escolas de fronteira com o objetivo de levar a educação e a pátria aos rincões mais distantes do território nacional. Em 1972 foi promulgada uma lei instituindo o regime das escolas de zonas e áreas de fronteira; o Dia das Escolas de Fronteira celebra a data de promulgação dessa lei, 14 de março, em homenagem a essas instituições nacionais defensoras da identidade argentina em seus limites territoriais (ver Ley 19.524, de 14 de março de 1972, disponível em http://www.saij.gob.ar/19524-nacional-regimen-escuelas-zonas-areas-frontera-lns000075 1 -1972-03-14/123456789-0abc-defg-g15-70000scanyel, última consulta em outubro de 2019). 
Estados-membros, assim como políticas públicas específicas que fomentam alguns intercâmbios educativos(Amaral 2016). ${ }^{2}$

A presente investigação busca compreender a experiência educacional de integração fronteiriça e a persistência da nação em duas escolas públicas de ensino fundamental que participam do Programa Escolas Interculturais de Fronteira (PEIF) - a escola Adele Zanotto (em Foz do Iguaçu, no Brasil) e a Escuela Intercultural Bilingüe 2 (em Puerto Iguazú, na Argentina). ${ }^{3}$ Essas instituições educacionais estão localizadas em áreas periféricas dessas duas cidades, que formam, juntamente com Ciudad del Este (Paraguai), a região conurbada da tríplice fronteira entre Argentina, Brasil e Paraguai. ${ }^{4}$

A investigação prioriza uma abordagem sobre a mobilidade transfronteiriça e as políticas de integração, com ênfase nas práticas cotidianas no âmbito educacional. A mobilidade é compreendida como "o movimento (de pessoas, de coisas, de ideias) com os significados e as narrativas que os circundam" (Cresswell 2009: 25). Nesse sentido, a mobilidade transfronteiriça significa o deslocamento espacial entre limites internacionais de pessoas, objetos, símbolos, ideias e imaginários que produzem novas dimensões do espaço social transfronteiriço, sendo este permeado por desigualdades, diferenças, relações de poder e articulações temporais e espaciais diferenciadas (Cresswell 2009; Schiller e Salazar 2013).

Já a fronteira, entendida tanto como barreira que separa quanto como ponte que integra, é um conceito polissêmico, sobredeterminado e heterogêneo (Balibar 2005). As fronteiras políticas, culturais e simbólicas serão abordadas, ao longo do artigo, a partir de três dimensões articuladas: (1) os dispositivos de mobilidade e controles de professores e alunos entre os dois territórios nacionais; (2) as diferenças e assimetrias no aprendizado das línguas em uma zona de contato; (3) os símbolos e narrativas de integração e de afirmação da nação acionados nos rituais do cotidiano escolar.

2 O Mercosul foi fundado pelo Tratado de Assunção, em 1991, sendo formado por Argentina, Brasil, Paraguai e Uruguai, e desde 2012 também por Venezuela. Este último país encontra-se atualmente suspenso dessa comunidade regional.

3 A pesquisa foi financiada pelo Conselho Nacional de Desenvolvimento Científico e Tecnológico (CNPq) e contou com a participação, na realização de observações de campo e de entrevistas, de Cecilia de Mar Zamudio Serrano, estudante da Maestría en Estudios de la Cultura y la Comunicación (México), em 2013. Parte da investigação foi apresentada na 29. ${ }^{a}$ Reunião Brasileira de Antropologia (RBA), em agosto de 2014. Gostaríamos de agradecer aos entrevistados, especialmente à diretora da escola Adele Zanotto, Cerilândia Batista (in memoriam). Agradecemos ainda aos pareceristas e à comissão editorial da revista Etnográfica.

4 As cidades de Foz do Iguaçu, Puerto Iguazú e a Grande Ciudad del Este (juntamente com Presidente Franco e Hernandarias) formam um conurbado trinacional de aproximadamente 800 mil habitantes, constituindo a região mais urbanizada das fronteiras do Brasil com os países vizinhos (Albuquerque 2015). 
A pesquisa de campo foi realizada por meio da observação etnográfica de práticas docentes nas salas de aula das duas escolas e do acompanhamento das mobilidades transfronteiriças das professoras. Além disso, entrevistamos diretoras, coordenadoras e professoras, conversamos com alguns alunos nas duas instituições educativas, principalmente nos anos de 2013 e 2014, e analisamos documentos oficiais do PEIF produzidos pelos governos do Brasil e da Argentina. ${ }^{5}$

\section{AS ESCOLAS DE FRONTEIRA E A MOBILIDADE DOCENTE}

O Projeto Escola Intercultural Bilíngue de Fronteira foi criado em 2005 a partir de um acordo entre os Ministérios de Educação da Argentina e do Brasil e se transformou oficialmente em Programa Escolas Interculturais de Fronteira (PEIF) em 2012. O PEIF insere-se numa política de integração transfronteiriça na área de educação básica. ${ }^{6} \mathrm{O}$ objetivo do programa é construir uma "identidade regional bilíngue e intercultural no marco de uma cultura de paz e cooperação interfronteiriça" (MECT/ME 2007: 2).

As quatro primeiras escolas que aderiram ao PEIF estavam localizadas em Dionísio Cerqueira (Santa Catarina, Brasil) e Bernardo de Irigoyen (Misiones, Argentina), Uruguaiana (Rio Grande do Sul, Brasil) e Paso de los Libres (Corrientes, Argentina). Em 2006, o projeto foi ampliado para outras cidades transfronteiriças, incluindo Foz do Iguaçu e Puerto Iguazú (MECT/ME 2007: 10). Em 2009 passou a ser efetivado em "cidades gêmeas" entre o Brasil e quatro países vizinhos (Uruguai, Argentina, Paraguai e Venezuela), contemplando 13 escolas brasileiras e 13 das nações limítrofes. ${ }^{7}$ Atualmente, o programa conta com 16 instituições educacionais brasileiras e 16 das nações vizinhas citadas e da Bolívia, totalizando 32 escolas. $^{8}$ No caso brasileiro, não se trata de escolas novas criadas particularmente para o programa, mas de instituições estaduais e municipais de ensino fundamental já existentes e localizadas em núcleos urbanos próximos ao limite internacional.

A Escola Municipal Adele Zanotto Scalco, localizada no bairro Vila Boa Esperança (Foz do Iguaçu), foi a primeira do município e do estado do Paraná

5 No período da realização da pesquisa, eram mulheres todas aquelas que participavam do programa: diretoras, coordenadoras e as professoras que realizavam o cruce entre as duas escolas.

6 O PEIF se constituiu como programa oficial do Ministério da Educação no Brasil pela portaria n. ${ }^{\circ} 798$, de 19 de junho de 2012. Entre 2005 e 2012, funcionou como algo mais experimental denominado Projeto Escola Intercultural Bilíngue de Fronteira (PEIBF).

7 Ver "Escola de Fronteira reúne cinco países", no Portal do Ministério da Educação, < http://portal.mec.gov.br/busca-geral/220-noticias/185 1327392/12217-escola-de-fronteira-reune-cinco-paises > (última consulta em outubro de 2019).

8 Ver "Escolas de fronteira", no Portal da Educação Integral do Ministério de Educação, < http:// educacaointegral.mec.gov.br/escolas-de-fronteira > (última consulta em outubro de 2019). 
a tomar parte do PEIF, em 2006. ${ }^{9}$ Começou somente com duas salas de aula do $1 .{ }^{\circ}$ ano do ensino fundamental e foi ampliando sua participação nos anos seguintes. Em Puerto Iguazú, o projeto se iniciou no mesmo ano na Escuela n. 164. Em 2009 foi inaugurado o edifício da nova instituição escolar: Escuela Intercultural Bilingüe 2, no bairro Las Leñas, com tempo integral e totalmente direcionada para o programa de integração transfronteiriça. ${ }^{10}$

O PEIF, em sua proposta pedagógica, visa construir uma aproximação de métodos e conteúdos na prática educativa dos docentes transfronteiriços. No primeiro ano de seu funcionamento, o objetivo era trabalhar a cultura e os costumes do país vizinho. As professoras investigavam sobre danças, músicas, folclore, vestimentas tradicionais ou comidas de cada nação e trabalhavam na sala de aula da escola da cidade vizinha. Depois passaram a adotar a pedagogia de projetos de aprendizagem a partir da assessoria do Instituto de Investigação e Desenvolvimento de Políticas Linguísticas (IPOL), no Brasil, e do Ministerio de Cultura, Educación, Ciencia y Tecnología de la Provincia de Misiones (МСЕСуT), na Argentina.

No início, os responsáveis pela formação docente do IPOL na escola brasileira trabalharam com temas transversais próximos à realidade local da fronteira, tais como cigarro, meio ambiente, lixo, dinheiro e crise argentina [Mariana, assessora do IPOL, 2014]. No entanto, esses temas transversais não se converteram necessariamente em conteúdos a serem ensinados às crianças, uma vez que o pressuposto da metodologia de ensino é partir do interesse dos alunos.

Os temas são eleitos pelas crianças e depois os professores das duas escolas se reúnem para planejar cada assunto selecionado em forma de projeto a ser desenvolvido em sala de aula por meio de diferentes atividades pedagógicas, durante um bimestre. A proposta visa discutir temáticas - animais, plantas, meio ambiente, ciclo da água, lendas, etc. - através da língua portuguesa na Argentina e da espanhola no Brasil. A instrução normativa não é ensinar português e espanhol como línguas estrangeiras, mas como segundo idioma, mediante distintos conteúdos interdisciplinares.

O PEIF instituiu também a mesma quantidade de horas de trabalho e de grupos de estudantes contemplados nas duas escolas. Em 2013 e 2014, abrangia oito salas de aula das séries iniciais $\left(1 .^{\circ}, 2 .^{\circ}, 3 .^{\circ}\right.$ e $4 .^{\circ}$ anos), com cerca de duas horas de aula em cada classe. Quatro professoras brasileiras se deslocavam, todas as quartas-feiras, para a Escuela Intercultural Bilingüe 2, e cada uma ensinava em duas classes pela manhã. Por sua vez, duas professoras argentinas

9 O colégio Adele Zanotto, em 2013, contava com 1250 alunos e 65 professores, com 30 salas de aula nos dois horários (manhã e tarde).

10 A Escola Intercultural Bilíngue tinha 14 professores e 400 alunos. É uma escola primária (1. ${ }^{\circ}$ a $7 .^{\circ}$ grados) de tempo integral. 
iam para a escola de Foz do Iguaçu duas vezes por semana, e também ensinavam em duas salas de aula a cada dia. ${ }^{11}$

A mobilidade docente é conhecida pelo termo em espanhol cruce. A palavra não se refere somente ao ato de atravessar o limite internacional entre as duas cidades, mas também ao próprio programa de intercâmbio e às aulas ensinadas na escola do país vizinho:

"O 'cruce' é a travessia, que em algumas fronteiras é a ponte; em outras, a balsa; em outra, apenas a rua. Mas cruzar, na dinâmica proposta para esse programa, é muito mais, pois coloca o professor no centro do processo à medida que é ele que leva a língua, a cultura e o conhecimento, mediando-os com os alunos da escola parceira. O professor articula, planeja e desenvolve projetos em conjunto com o colega argentino, paraguaio, venezuelano e uruguaio. O 'cruce' é o modo como se operacionaliza a principal ação da Escola Intercultural, baseada na troca dos docentes" (Sturza 2014: 5).

O cruce é, portanto, um dos regimes de mobilidade que configura esse espaço transfronteiriço. Além dessa circulação docente, vários outros deslocamentos cotidianos de curta distância atravessam os limites nacionais e se efetivam geralmente por razões comerciais, de trabalho, de atendimento à saúde e à educação, e por causa das redes de amizades e parentescos (Delgado e Ortiz 2012). Essas mobilidades são impulsionadas especialmente pelas assimetrias econômicas, políticas e sociais existentes de um lado e outro dos limites internacionais. Nesse caso específico, o deslocamento semanal das professoras argentinas e brasileiras do PEIF se concretiza de maneira circular (idas e voltas) e está vinculado a uma política pública interestatal de promoção da integração transfronteiriça. No entanto, não se trata somente da mobilidade das docentes, uma vez que estas levam "a língua, a cultura, o conhecimento" e produzem novas fronteiras culturais e simbólicas na interação cotidiana com os professores e alunos da escola do país vizinho. Além disso, esse deslocamento também produz formas de classificação e imaginação relacional entre "nós" e "eles".

As professoras são classificadas, nesses espaços educacionais, como as que fazem e as que não fazem o cruce, produzindo determinadas diferenças simbólicas. Aquelas que o realizam constroem uma experiência transfronteiriça singular por meio da percepção de semelhanças e diferenças entre os dois lados da fronteira. Elas descobrem, em seu exercício profissional, alguns contrastes importantes entre as estruturas escolares, o trabalho docente, os salários e o comportamento dos alunos. No documento oficial de 2007, essas instituições

11 A ampla maioria das salas de aula não é contemplada pelo programa na escola Adele Zanotto. Somente o $1 .^{\circ}$ ano do ensino fundamental há 11 salas de aula e somente uma fazia parte do PEIF em 2014. 
pares eram chamadas de "escolas-espelhos". Talvez essa imagem do espelho, capaz de refletir a própria imagem no reflexo do outro, seja uma boa metáfora para pensar como professoras, diretoras e coordenadoras imaginam a alteridade na circulação semanal.

A questão salarial é a primeira diferença pontuada pelas docentes brasileiras. Elas afirmam que não recebem uma contribuição extra para fazer o cruce, diferentemente das professoras argentinas, que são remuneradas com um salário em dobro. Ressaltam que não há tempo para o planejamento das atividades, pois não se dedicam somente ao programa. Elas se comprometem durante a semana com suas aulas no Brasil e é justamente no dia livre para planejamento semanal que se ocupam das aulas na escola argentina.

Com toda essa falta de incentivo e de tempo livre para planejamento, quase nenhuma docente brasileira deseja participar do programa. "A briga aqui é que ninguém quer aceitar o projeto em sua sala de aula. Ninguém quer fazer o cruce e poucas [docentes] aceitam as colegas argentinas em sua sala de aula também". ${ }^{12}$ Estabelece-se então a comparação permanente: "lá obrigam: vai ser em tua sala e pronto; aqui, tem uma resistência" [professora da Adele Zanotto, 2013]. ${ }^{13}$

No lado argentino, a coordenadora e diretora ressaltam que toda a instituição educacional está envolvida com o programa. Todos os professores ganham um duplo salário básico, por se tratar de uma escola de tempo integral. Há um sistema rotativo entre as docentes que vão ensinar no colégio brasileiro. As professoras que fazem o cruce se dedicam somente às suas atividades didáticas em Foz do Iguaçu. A rotina de trabalho semanal é distribuída em dois dias de planejamento, juntamente com a assessora pedagógica (segundas e quartas), dois dias de aula no Brasil (terças e quintas) e um dia de avaliação das atividades da semana (sexta-feira).

As principais reclamações das argentinas em relação à escola Adele Zanotto são referentes ao comportamento dos alunos, vistos como inquietos, indisciplinados, barulhentos e com muitas dificuldades na compreensão do espanhol. Elas narram que não conseguem ficar sozinhas com esses estudantes, sendo necessária a presença constante da professora regente da sala de aula. ${ }^{14}$ As docentes de Puerto Iguazú reclamam também da pouca participação dos

12 Em março de 2014, a realidade na Adele Zanotto já era um pouco diferente. As professoras que faziam o cruce recebiam um valor extra pelas horas trabalhadas, tinham tempo para planejamento das atividades do projeto e somente assumiam na escola brasileira aulas de reforço.

13 Preservamos os nomes reais das diretoras, coordenadoras e professoras do PEIF entrevistadas, por serem conversas autorizadas pelas interlocutoras, mas tivemos o cuidado de não identificar os nomes dos entrevistados em trechos que pudessem prejudicar as relações com os professores ou outros agentes da escola do país vizinho.

14 Professora regente é a docente principal daquela turma específica, uma vez que há também professores de apoio ou auxiliares em algumas turmas. 
pais na instituição educacional brasileira, visto que muitos deles não sabem nem da existência do programa. Já as docentes brasileiras na escola argentina valorizam a disciplina e a hierarquia na relação entre professor e aluno, o esforço de aprendizagem das crianças, mas criticam a falta de recursos didáticos, o que dificulta a realização de determinadas atividades propostas.

Essas imaginações sobre "nós" e "eles" são variáveis, dependendo da conjuntura favorável ao desenvolvimento do programa em cada país. Assim, já houve contextos em que a situação esteve mais difícil na Argentina do que no Brasil em termos de planejamento, já que a escola Adele Zanotto contava com uma presença mais ativa do IPOL. Em 2010 o Ministério da Educação do Brasil encerrou a parceria com esse instituto e transferiu as atividades de planejamento e formação do programa para as universidades públicas mais próximas das escolas. No caso de Foz do Iguaçu, a instituição de ensino superior selecionada foi a recém-inaugurada Universidade Federal de Integração Latino Americana (Unila), que passou a atuar desde 2011 . Entretanto, os professores universitários responsáveis não recebiam, por parte do Ministério da Educação, orientações claras e formação específica para trabalhar no PEIF. Havia bastante reclamação por parte das docentes da escola brasileira sobre a falta de formação continuada e de planejamento nos anos iniciais de atuação da Unila.

O PEIF no Brasil e na Argentina continua com indefinições programáticas e descontinuidades. ${ }^{15}$ As diferenças dos sistemas nacionais e provinciais/estaduais de ensino entre os países, suas legislações e práticas políticas e pedagógicas criam barreiras e dificuldades no funcionamento das escolas de fronteira, ainda que essas instituições escolares se localizem somente a alguns quilômetros de distância uma da outra. E esses rearranjos, sensíveis às variações políticas em distintas escalas de poder, funcionam como pêndulos que ora parecem indicar que estão melhores de um lado, ora se apresentam mais organizados do outro lado, conforme as lentes dessas professoras que transitam entre os dois espaços educacionais.

\section{Controle do trânsito dos alunos na alfândega argentina}

As docentes cruzam, mas os alunos continuam sem conhecer os estudantes da "escola-espelho". Como são crianças, há dificuldades do cruzamento por falta de documentação e dada a necessária autorização e acompanhamento dos pais. Não tinha existido nenhuma ocasião de interação direta entre os alunos das duas escolas entre 2006 e 2014. A diretora em Puerto Iguazú ressalta que

15 O PEIF não funcionou formalmente entre as duas escolas no ano de 2017. O governo argentino não autorizou o cruce e no Brasil faltaram incentivos básicos para o deslocamento das professoras, ainda que estas tenham realizado o intercâmbio informalmente. A ascensão de novos governos em 2016 nos dois países, não identificados com as políticas de integração regional dos presidentes anteriores, tem prejudicado o funcionamento dessa política educacional de cooperação transfronteiriça. 
é preciso a autorização dos pais, mas há vários casos de pais separados, dificultando essa autorização:

"Os meninos, os menores de idade, para cruzar a fronteira, devem cruzar com mamãe e papai, se têm os pais separados já não podem cruzar se não têm uma autorização. No que se refere aos menores de idade não existe nenhuma permissão, nenhuma regulação, nenhum instrumento, não há" [Sandra, diretora, 2013, tradução nossa].

Em 2012 havia a intenção de fazer o duplo cruzamento dos estudantes pela primeira vez. A instituição escolar de Foz do Iguaçu chegou a tirar fotocópias dos documentos de identidade dos alunos. Entretanto, as mudanças políticas municipais e a burocracia da alfândega argentina terminaram inviabilizando essa iniciativa. De acordo com a supervisora da escola brasileira,

"na verdade existe uma burocracia muito grande na entrada da Argentina. A criança tem que ter identidade e ser acompanhada de seu pai e mãe. Se está só com a mãe, tem que ter autorização de um juiz de Vara de Infância e Juventude. [...] Então, [no nosso caso] dependia de um acordo do consulado brasileiro e argentino. E o responsável do consulado na prefeitura ficou de ver isso e simplesmente abandonou. Mudou a política, a administração, e ele se afastou da função. Então nós não fomos mais atrás porque não dependia da escola" [Marlene, supervisora, 2013].

A barreira da alfândega argentina, as legislações específicas de proteção aos menores de idade e o medo de tráfico de crianças nas fronteiras internacionais são obstáculos à efetiva aproximação entre os estudantes e à realização de atividades conjuntas.

O cruzamento de agentes educacionais entre as duas escolas ocorre mediante diferentes controles fronteiriços. A alfândega argentina ${ }^{16}$ é a materialização visível do Estado territorial durante o cruce de toda semana (Grimson 2003). As professoras que participam do programa devem sempre sair com antecedência, pois no percurso entre as duas instituições educacionais cruzam com a fiscalização na aduana argentina e o tempo gasto nas filas de controle fronteiriço é variável, conforme o ritmo do fluxo de carros entre os dois países. A fronteira estatal opera, nesse caso, mediante a fiscalização dos documentos de identidade dos professores na ida e na volta, proibições dos alunos menores de idade e permissões especiais na circulação dos materiais didáticos entre as duas instituições escolares.

16 Há também uma aduana brasileira, geralmente sem fiscalização; de fato, o controle diário de pessoas e mercadorias ocorre na alfândega argentina. 
Dessa forma, os intercâmbios entre os alunos das duas escolas, nos anos iniciais do PEIF, ficam mais restritos ao envio de mensagens, fotografias e outras formas de correspondência por intermédio das professoras, assessoras e diretoras, e atualmente das redes sociais. ${ }^{17}$ Cruzam imagens, escritos, mensagens de carinho e alguma curiosidade de conhecer aqueles que estão do outro lado da fronteira política. ${ }^{18}$ Por outro lado, a mobilidade docente modifica o cotidiano escolar dos estudantes que não atravessam a fronteira política e produz espaços de interação cultural e linguística entre professoras e alunos na escola do país vizinho.

Nessa perspectiva, os alunos que fazem parte do PEIF ressaltam a importância do programa para aprender uma segunda língua com uma professora nativa, porque "quando eu for para outros países vou poder conversar com essas pessoas" [Marília, 2016] ou "eu gosto de espanhol porque dá para conversar com os turistas" [Lúcio, 2016]. ${ }^{19}$ A justificativa pode ser ainda a admiração da docente, que fala de maneira natural um idioma que a criança desconhece: "eu gosto da aula de espanhol porque eu quero falar igual à professora" [Mayara, 2016]. Mesmo que os alunos não cruzem a fronteira entre as duas escolas, suas narrativas e expectativas produzem significados sobre a mobilidade e o encontro com o outro, distante ou próximo, pela mediação da língua aprendida. A compreensão não dualista entre fixidez e mobilidade nessa dinâmica transfronteiriça ajuda a perceber outras dimensões de deslocamento presentes nas experiências e imaginários estudantis, ainda que sejam vistos como os agentes mais fixos em comparação com a mobilidade das docentes (Schiller e Salazar 2013).

\section{AS ASSIMETRIAS DAS LÍNGUAS NAS ESCOLAS DE FRONTEIRA}

O Estado tem fomentado uma nova política de línguas nas escolas de fronteira: o aprendizado do bilinguismo português-espanhol. Mas as realidades específicas das línguas em contato obedecem a dinâmicas próprias e vão além das políticas linguísticas, constituindo uma dimensão privilegiada de observação sobre as assimetrias de poder entre as nações vizinhas. Há processos de integração cultural e de bilinguismo que ocorrem independentemente das

17 As duas escolas contam atualmente com páginas no Facebook e são publicadas fotos dos alunos durante as diversas atividades realizadas pelas professoras que fazem o cruce.

18 Em outras localidades de fronteira entre o Brasil e a Argentina, como Bernardo de Irigoyen e Dionísio Cerqueira, há menos controles, e as crianças podem desenvolver atividades em comum entre as escolas que participam do PEIF.

19 Os nomes dos alunos citados são fictícios. As frases transcritas, escritas pelas crianças do $1 .{ }^{\circ}$ ao 5. ${ }^{\circ}$ ano da escola Adele Zanotto, foram formuladas durante uma atividade de desenho sobre a importância do aprendizado da língua espanhola no âmbito do PEIF, coordenada pelas professoras Jorgelina Tallei e Laura Amato, da Unila. O material foi gentilmente cedido pelas docentes para esta investigação. 
ações dos Estados nacionais. É importante compreender o poder dos meios de comunicação e dos fluxos migratórios capazes de produzir assimetrias entre os países, inclusive em seus contextos transfronteiriços.

$\mathrm{Na}$ zona de fronteira Brasil/Argentina, a língua portuguesa é mais valorizada do que o espanhol e é vista, por muitos argentinos, como idioma de maior prestígio (Sturza 2006). A posição hegemônica do Brasil nas últimas décadas no Cone Sul ajuda a produzir, por parte das populações situadas em áreas de fronteira, imaginários assimétricos do poder simbólico entre as línguas. ${ }^{20}$ O idioma da "potência regional" chega aos lares dos argentinos que vivem próximo do limite internacional por meio de canais de televisão e frequências de rádio brasileiros:

"Nós aqui ligamos a rádio e te asseguro que tu encontras dez rádios brasileiras e duas rádios argentinas. Ligamos a televisão, temos Record, Globo, SBT, todos os canais e somente há dois argentinos, CBI local e Canal 12 que se pode ver" [Mirian, coordenadora pedagógica, 2013, tradução nossa].

As letras, melodias e ritmos das músicas brasileiras também atravessam essa fronteira. Parte do encantamento que os argentinos sentem pelo português ocorre por meio das músicas. Além disso, vários habitantes das zonas transfronteiriças da Provincia de Misiones são descendentes de brasileiros e os pais ou/e avós continuam utilizando o português como idioma doméstico:

"Nós já temos uma sensibilização, os alunos já falam o português em casa, não o português mas o portunhol. Não são todos, mas há alunos que vêm à escola e falam o espanhol e o português. Mas voltam para suas casas e falam só o português. Seus pais são brasileiros" [Sandra, diretora, 2013, tradução nossa].

Assim, em relação ao conhecimento da cultura e língua do outro país, temos uma situação bastante assimétrica nessa região de tríplice fronteira. Como já constatado no documento oficial do PEIF, parte dos alunos argentinos já é efetivamente bilíngue, enquanto que os estudantes brasileiros são majoritariamente monolíngues (MECT/ME 2007: 11). Uma pequena parte dos estudantes da escola Adele Zanotto é descendente de paraguaios ou mantém vínculos familiares e comerciais com Ciudad del Este (Paraguai), tendo maior facilidade na compreensão das aulas em espanhol. Há também alguns alunos

20 O prestígio da língua espanhola na fronteira Brasil/Argentina e os fluxos através do Rio da Prata foram predominantes até meados do século XX. Na mudança do pêndulo do poder no Cone Sul a partir da década de 1970, o Brasil se torna o país mais poderoso dessa área subcontinental. Essa nova geopolítica regional gera diferenças nas formas de apreciações das línguas de contato nas fronteiras entre os dois países (Sturza 2006). 
descendentes de argentinos, como a aluna Florencia, do $4 .^{\circ}$ ano da Adele Zanotto, cujo pai é argentino. Ela demonstra contentamento quando lê na lousa "clase en español". Durante as aulas, é esta criança que mais responde às questões formuladas pela professora e a única da sala que conhece a cidade vizinha de Puerto Iguazú.

Nas salas de aula das escolas argentina e brasileira é possível perceber as diferenças em relação à aprendizagem da segunda língua. As crianças da Escuela Intercultural Bilingüe 2 se comunicam mais em português, algumas inclusive falam a língua portuguesa sem o sotaque do espanhol e conseguem compreender a fala da professora e responder às atividades orais solicitadas. A dificuldade está mais na escrita do português. Na escola brasileira, por sua vez, as dificuldades de escuta, fala e escrita do espanhol são bem mais acentuadas. Em uma aula sobre preservação ambiental, a professora explica a atividade em espanhol e existe uma lista de palavras fixada na lousa com a tradução para o português. A ideia é ir formando um dicionário entre as duas línguas ao longo do ano letivo. A maioria dos estudantes não consegue repetir as frases pronunciadas em espanhol. As crianças brasileiras costumam responder em português. Quando a professora argentina pergunta o significado em português de algumas palavras, os alunos têm dificuldades em responder e facilmente confundem os falsos cognatos.

As assimetrias de aprendizado das línguas são reforçadas atualmente nas próprias instituições escolares. Os estudantes da Escuela Intercultural Bilingüe 2, além das atividades do PEIF, têm aulas semanais de português como língua estrangeira a partir do $1 .^{\circ}$ ano, enquanto que parte dos alunos da escola Adele Zanotto têm o contato com o espanhol somente durante as duas horas semanais com a professora argentina. ${ }^{21}$ Como o programa somente funciona em oito salas de aula, muitos alunos da escola brasileira não participam do PEIF. ${ }^{22}$ Diferentemente das crianças argentinas, os alunos brasileiros também não têm contato com esse idioma no ambiente familiar. Poucos estudantes assistem os canais de televisão paraguaios em Foz do Iguaçu e quase ninguém consegue sintonizar os canais argentinos (Thomaz e Altamiranda 2010). Uma

21 A Argentina promulgou em 2008 uma lei tornando obrigatório o ensino do português nas escolas primárias das províncias fronteiriças com o Brasil (ver Ley 26.468, de 17 de dezembro de 2008, disponível em <http://www.saij.gob.ar/26468-nacional-propuesta-curricular-ensenanza-idioma-port ugues-todas-escuelas-secundarias-sistema-educativo-nacional-lns0005502-2008-12-17/123456789 -0abc-defg-g20-55000scanyel >, última consulta em outubro de 2019).

22 A professora Laura Amato, da Universidade Federal da Integração Latino Americana (Unila), desenvolveu o projeto de extensão "Fronteira Intercultural" entre 2014 e 2017, justamente nas classes em que as crianças não tinham contato com o espanhol. Os bolsistas do projeto ensinavam diversos temas dos países da América Latina por meio da língua espanhola e possibilitavam que a educação intercultural estivesse presente em algumas das salas de aula não contempladas pelo PEIF (Amato e Ruiz 2017). 
das justificativas que usam é que os sinais dos países limítrofes não chegam com boa qualidade no lado brasileiro, além de não demonstrarem interesse em sintonizar nos programas televisivos das nações vizinhas:

"Nossos alunos não escutam e nem olham a programação em espanhol. Os canais argentinos só pegam bem nas casas que têm TV a cabo. Lá não, nossa televisão passa normalmente. Lá eles gostam do português, aqui parece que há mais resistência. Também pela falta de costume. [No Brasil] eles escutam, assistem, conversam tudo em português" [Terezinha, docente, 2013].

As diferenças dos usos dos idiomas entre os alunos dos dois lados da fronteira se reproduzem, às vezes, nas próprias práticas das docentes que realizam o intercâmbio. De acordo com a coordenadora pedagógica e a diretora da escola em Puerto Iguazú, as professoras argentinas gostam do Brasil e se interessam em aprender o português e saúdam as colegas brasileiras nesse idioma quando chegam à escola em Foz do Iguaçu. Conforme algumas interlocutoras argentinas, as docentes brasileiras não se interessam pela Argentina da mesma forma e nem se esforçam em cumprimentar em espanhol quando chegam à escola em Puerto Iguazú: "tentamos falar em português quando os professores brasileiros chegam, mas eles não vão tentar falar em espanhol. Tem essa barreira aí. É como uma barreira ideológica, mas existe, está aî" [professora da Escuela Intercultural 2, 2013, tradução nossa). O regime de mobilidade específico de docentes se conecta com outras formas de mobilidades, assimetrias e relações de poder historicamente construídas e (re)produzem barreiras, diferenças e desigualdades entre os dois espaços escolares (Schiller e Salazar 2013).

As línguas de fronteira são gramáticas culturais sensíveis para pensarmos assimetrias de poder em diferentes escalas, mas também códigos simbólicos que decifram as complexas relações entre formas populares e estatais de classificação das línguas em suas zonas de contato. Na tríplice fronteira entre Argentina, Brasil e Paraguai, os idiomas escolares de cada país são respectivamente espanhol, português e espanhol/guarani. Entretanto, nas conversas cotidianas de adultos, jovens, inclusive das crianças nos espaços educacionais estudados, os habitantes transfronteiriços costumam classificar os idiomas como castelhano, brasileiro e paraguaio. Conforme uma estudante do $2 .^{\circ}$ ano primário da escola argentina: "eu sou brasileira, meus pais são brasileiros. Em minha casa não se fala castelhano, fala brasileiro" [María, 2013]. Já Artur, aluno do 2. ${ }^{\circ}$ ano do ensino fundamental na escola brasileira e descendente de pais paraguaios, comenta: "minha mãe fala em paraguaio e meu pai também" [Artur, 2013].

Nessa linguagem diária, geralmente se estabelece uma relação entre o nome do país, a identidade nacional e a língua, embora no caso argentino o termo nativo mais usual seja castelhano, e não argentino. A referência ao idioma castelhano 
desde o período colonial das "Índias de Castela" (Holanda 2000 [1959]) talvez seja um elemento relevante para entender a persistência do uso popular, não somente na Argentina, mas também em outros países latino-americanos. Já os termos "língua brasileira" e "fala paraguaia" indicam a equivalência semântica entre nação e língua, tão comum em vários países europeus. Essas expressões, no contexto das nações americanas, podem representar formas cotidianas de substituição das nomeações oficiais das línguas (portuguesa e espanhola) que remetem às nações colonizadoras. Além disso, a "fala em brasileiro", no contexto da Província de Misiones, e a "fala paraguaia", no cenário da tríplice fronteira, simbolizam misturas linguísticas marcadas pela oralidade - respectivamente, o "portunhol"23 misionero dos descendentes de brasileiros na Argentina, e o jopará (mescla) entre espanhol e guarani no Paraguai.

Mais que buscar as origens históricas dessas classificações cotidianas dos idiomas nessa região de fronteiras, o que gostaríamos de apontar é uma maneira de pensar as línguas como gramáticas simbólicas da identidade nacional em zonas de contato com outros idiomas e com as formas de classificação escolares. Como as crianças se referem sempre à "língua brasileira", a professora logo corrige: "português, Maria, não é correto dizer língua brasileira" [Terezinha, docente, 2013]. ${ }^{24}$ Nas relações cotidianas entre docentes e alunos nas escolas de fronteira, se estabelecem diálogos e correções entre línguas que revelam sutilezas das relações de poder no âmbito educacional.

Nessas zonas de fronteira, as línguas e as identidades das novas gerações estão, muitas vezes, em disputa. A aprendizagem dos idiomas por parte dos filhos de casamentos mistos em Puerto Iguazú pode simbolizar justamente essa tensão, ou seja, quem tem o poder de determinar a língua de origem no aprendizado das crianças: "meu pai é brasileiro, meu pai não fala tanto brasileiro porque minha mãe não queria que eu falasse em português" [Juan, 2013]. Talvez essa proibição da mãe seja derivada de certo entendimento de que o menino não vai compreender bem nenhuma das duas línguas em contato e vai falar em "portunhol", tendo dificuldades no processo de alfabetização escolar. Como a criança vive em território argentino, seria melhor falar corretamente o castelhano. Entretanto, essa situação específica pode ser modificada, uma vez que ela está frequentando agora uma escola que valoriza o bilinguismo (português e espanhol).

23 O "portunhol" (mescla variada entre português e espanhol) atualmente não está restrito à oralidade. Há uma produção de escrita, especialmente em poesia, nas zonas de fronteira entre Brasil e os países vizinhos nas duas últimas décadas, inclusive o irreverente movimento literário do "portuñol salvaje" (Mota 2014).

24 Essa diferenciação entre a oralidade da "língua brasileira" e a escrita do "português da escola" já foi abordada na tese de doutorado de Pereira (1999), no contexto de uma comunidade rural de descendentes de alemães no estado do Paraná. 
Em suma, as línguas são símbolos de diferenciação e hierarquia nacional nos contextos de fronteiras internacionais e em tantos outros cenários interculturais. Outros símbolos e rituais (Turner 2005) também fazem parte do cotidiano escolar, operam em situações concretas e dão significação cotidiana às práticas educacionais nessas duas escolas.

\section{SÍMBOLOS E NARRATIVAS DA INTEGRAÇÃO \\ E DA NAÇÃO NO COTIDIANO ESCOLAR}

A busca de uma relação mais próxima entre os dois países se expressa mediante símbolos de integração na entrada dos colégios. Na Escuela Intercultural Bilingüe 2 existe um cartaz com a inscrição "Bem vindos/Bienvenidos", junto às bandeiras do Brasil e Argentina. Na Adele Zanotto, perto da diretoria, há a frase "Escola Intercultural", acompanhada de um desenho da pomba da paz segurando uma corrente com um coração, sendo metade colorida com as cores da bandeira argentina e outra metade com a bandeira brasileira.

A bandeira é um símbolo de identificação coletiva capaz de traduzir sentidos de pertença. As bandeiras do Brasil e da Argentina são imagens simples que condensam a imaginação nacional, objetos consagrados a produzir a ilusão de fixidez e eternidade dessas comunidades imaginadas modernas (Anderson 2008). Uma atenção especial aos espaços, tempos, movimentos e ações coletivas em torno das bandeiras poderia transformar esse naturalizado emblema cotidiano em objeto de estudo antropológico e sociológico (Billig 1998).
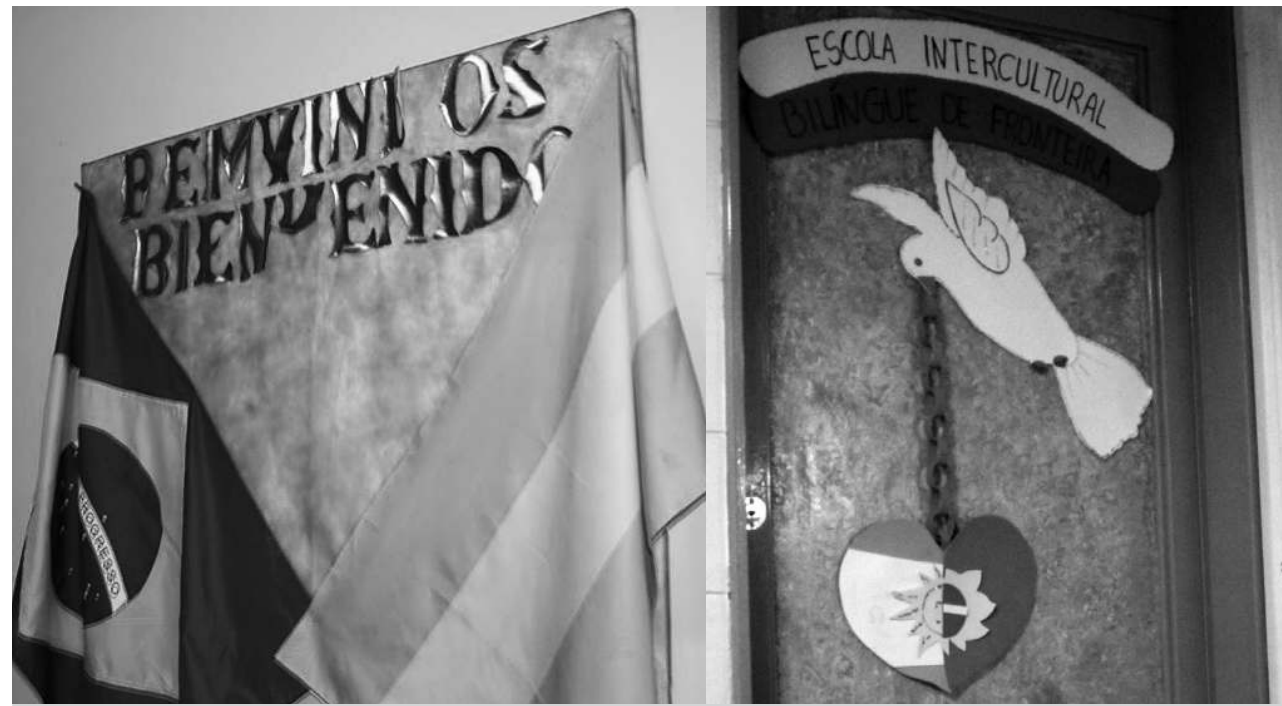

Figura 1 - Bandeiras nacionais e simbologias da integração: Escuela Intercultural Bilingüe 2 (esquerda) e escola Adele Zanotto (direita). Fonte: Arquivo da pesquisa de campo. 
As bandeiras são símbolos de unidade, identidade e diferença das nações. Nessas imagens das escolas de fronteira, elas estão irmanadas por um sentimento de paz e de fusão de experiências compartilhadas. São representações idealizadas dos desejos de integração que ocultam os conflitos, paradoxos e diferenças cotidianas das práticas sociais concretas.

$\mathrm{Na}$ experiência das atividades educacionais diárias e semanais, as bandeiras e os hinos nacionais de cada nação continuam separados. Nenhuma das duas escolas hasteia a bandeira e canta o hino do país vizinho. Na instituição educacional brasileira, todas as sextas-feiras, pela manhã e ao final da tarde, as crianças erguem a bandeira e cantam o hino nacional brasileiro. ${ }^{25} \mathrm{Na}$ Escuela Intercultural Bilingüe 2 , todos os dias os meninos e meninas ficam de pé diante da bandeira nacional no pátio do colégio e falam, em voz solene, a letra de saudação à bandeira. ${ }^{26}$

Esse ritual diário de reverência à bandeira argentina pode ser problematizado a partir da percepção contrastiva das professoras brasileiras que participam do PEIF:

"Na Argentina eles fazem uma declaração de amor à bandeira. O civismo lá é muito forte. Todo dia é sagrado, na entrada e na saída, eles fazem assim. Não é o hino que eles cantam. O hino é cantado só quando tem um ato cívico, uma apresentação, porque lá eles comemoram muito mais datas cívicas que nós aqui. De segunda a sexta, é sagrado, não entram na sala de aula sem esta declaração de amor à bandeira. Não é cantado, é falado. Tipo uma oração à bandeira, uma reza. Todas as crianças, juntamente com uma professora, ficam diante da bandeira, com grande respeito" [Terezinha, docente, 2014].

Os ritos de identidade nacional do país vizinho são observados com estranhamento por essa professora, permitindo que ela faça uma descrição minuciosa dos passos principais desse culto à bandeira no pátio da escola. Sua observação permite realizarmos aproximações com algumas considerações teóricas sobre a formação das nações e dos nacionalismos. Para autores como Anderson (2008) e Smith (2006), as práticas simbólicas de atualização das nações guardam similitudes com as comunidades religiosas, especialmente

25 No Brasil, desde 2009, existe uma lei nacional que obriga todas as crianças do ensino fundamental (do $1 .{ }^{\circ}$ ao $9 .^{\circ}$ ano) das escolas públicas e privadas do país a cantar o hino nacional uma vez por semana (ver Lei n. ${ }^{\circ}$ 12.031, de 21 de setembro de 2009, disponível em < http://www.planalto.gov.br/ ccivil_03/_Ato2007-2010/2009/Lei/L12031.htm >, última consulta em outubro de 2019).

26 Saudação à bandeira: "Salve, Argentina, bandeira azul e branca, punhado do céu onde reina o sol; a mais nobre, a mais gloriosa e santa; o firmamento sua cor lhe deu. Eu te saúdo, bandeira de minha pátria, sublime signo de liberdade e honra, jurando te amar, como também te defender, enquanto palpita meu coração fiel" (letra e música de Leopoldo Corretjer, tradução nossa). 
por meio do apego emotivo aos símbolos, emblemas e rituais de reprodução diária dessas imaginações coletivas em um mundo em processo de secularização.

Mas a reprodução da nação não se restringe ao símbolo da bandeira. A narrativa nacional se constrói cotidianamente no espaço escolar. Os livros didáticos, nas séries iniciais de ensino fundamental, apresentam geralmente as datas comemorativas da história nacional e dos territórios estaduais/provinciais e municipais do país onde que os alunos estão inseridos, construindo uma narrativa pedagógica da nação (Bhabha 2003), marcada pelo tempo linear dos fatos históricos e pela repetição anual das datas comemorativas.

Os alunos fazem, às vezes, apresentações teatrais dessas datas comemorativas do calendário nacional. No caso da Escuela Intercultural Bilingüe 2, vale destacar o registro de 2014 da efeméride de 2 de abril - Día del veterano y de los caídos en la Guerra de Malvinas -, data do início do conflito armado entre Argentina e Inglaterra, em 1982, e um dos símbolos contemporâneos do nacionalismo argentino. ${ }^{27}$ Todas as crianças, juntamente com as professoras, ficam no pátio do colégio em pé para ver a apresentação. No fundo do palco, tem um grande cartaz em tecido com as imagens desenhadas do soldado argentino e da bandeira nacional hasteada no mapa das ilhas Malvinas. Do lado esquerdo, dois alunos seguram uma cartolina com um mapa das ilhas desenhado pelas crianças e pintado de cor preta. Durante o ato cívico, eles colocam uma colorida bandeira argentina sobre este mapa. Alguns estudantes, uns vestidos de soldados e outros com o fardamento escolar, apresentam então os fatos marcantes da guerra e a versão nacional de que aquele território perdido para os ingleses é parte constitutiva da nação argentina.

Além disso, os estudantes de cada escola continuam participando, de maneira separada, dos ritos públicos em torno das datas de comemoração nacional, como o desfile da Revolução de 25 de Maio em Puerto Iguazú e o 7 de Setembro em Foz do Iguaçu. Por razões já relatadas, os alunos de cada país não participam nesses atos cívicos na cidade vizinha e geralmente não os conhecem. ${ }^{28}$

Há, portanto, territorialidades, tempos históricos e escolares distintos entre um país e outro e essas diferenças estão presentes no cotidiano educacional.

27 A Guerra das Malvinas ocorreu de 2 abril a 14 de junho de 1982 entre a Argentina e o Reino Unido. O começo do conflito se deu quando os soldados argentinos ocuparam a ilha sob o domínio britânico, distante 464 quilômetros da costa argentina. A Inglaterra reagiu, recuperou o território e derrotou o exército argentino.

28 As professoras e outros funcionários dessas escolas são convidados para participar dos desfiles comemorativos na cidade vizinha. As docentes vão com a farda escolar e desfilam com os alunos do país vizinho. Algumas professoras gravam vídeos, tiram fotos e as mostram para seus alunos em seu país. Entretanto, esses eventos cívicos não foram ainda transformados em projetos a serem discutidos em suas salas de aula. 
De acordo com a diretora da Adele Zanotto, já houve uma proposta de organizar um calendário de datas comemorativas nas duas escolas. A ideia seria que

"fosse possível a precisão das datas comemorativas da Argentina e se pudesse comemorar aqui na escola ou destacar. E as datas do Brasil, também comemorar lá. Mas não foi possível, porque nosso calendário é bem diferente em comparação ao calendário argentino. $\mathrm{O}$ início das aulas, as datas comemorativas. Na época, a secretária de educação municipal achou que era melhor não criar um calendário único" [Cerilândia, diretora, 2013].

Os ritmos próprios dos calendários escolares traduzem temporalidades territorializadas, produzem o tempo homogêneo e simultâneo em um determinado território nacional (Anderson 2008). Os calendários escolares dividem o tempo anual, fixam períodos de aula e de férias que movimentam e ritualizam a vida coletiva nas sociedades contemporâneas. Pensar em uma proposta de calendário comum entre as duas instituições educacionais é problematizar as fronteiras temporais das nações inscritas em seus rituais e tempos escolares.

Os símbolos e narrativas da nação ainda têm mais expressão no cotidiano dessas escolas que as representações e formas de contar uma história transfronteiriça, mesmo quando o projeto de aprendizagem tem o objetivo de conhecer a cultura do país vizinho. O projeto sobre folclore, por exemplo, visava ensinar e aprender sobre histórias, personagens, lendas e mitos da nação limítrofe e construir similitudes com as narrativas mais familiares e conhecidas pelos alunos brasileiros ou argentinos. Ainda que despertem curiosidades sobre a alteridade nacional e as similitudes com o folclore local, são projetos que geralmente reforçam a existência das nações como realidades dadas, naturalizadas e homogêneas.

Num sentido de uma construção mais transfronteiriça, vale destaque o projeto de aprendizagem sobre os parques ambientais de Iguaçu, uma vez que essa iniciativa contribuiu para construir uma perspectiva de espaço natural comum, diminuindo os referentes nacionais e construindo algumas pontes de uma geografia conjunta entre os dois países. Entretanto, ainda não foram desenvolvidas atividades mais direcionadas a pensar a história e a geografia locais e que contemplem as narrativas da região da tríplice fronteira de maneira integrada.

Dessa forma, podemos concluir que algumas práticas cotidianas de construção da integração e da nação nessa região de fronteira se configuram em espaços escolares singulares que atravessam e transcendem a zona de fronteira. A produção da integração nessa experiência educativa é fundamentalmente um ato político e pedagógico consciente que se efetiva de diferentes formas: o programa de mobilidade docente, os seminários e cursos de formação para os professores do PEIF e o planejamento de atividades a serem executadas na escola do país vizinho, além da criação de símbolos de união entre os dois países e as 
tentativas de pensar um calendário letivo em comum. Por outro lado, a invenção cotidiana da nação se concretiza de forma mais inconsciente e naturalizada por meio dos livros didáticos, dos mapas, dos calendários escolares e seus ritmos anuais, das datas comemorativas e dos desfiles públicos. Essa maneira de produzir a nação nessas escolas não difere da de outros contextos educacionais não fronteiriços, mas na zona de fronteira é percebida como algo a ser problematizado pelo olhar atento e contrastante das docentes do país vizinho.

\section{CONSIDERAÇÕES FINAIS}

As escolas de fronteira criam pontes simbólicas. São processos políticos, sociais e culturais atravessados por ideais e práticas de intercâmbios transfronteiriços de docentes, materiais didáticos, experiências pedagógicas, condutas profissionais, línguas, culturas, símbolos, valores, normas e desejos de integração. O regime de mobilidade docente entre as duas escolas observadas apresenta múltiplas conexões com outros deslocamentos transfronteiriços (migrações, turismo internacional, comércio de fronteira, redes familiares e de amizade, meios de comunicação, entre outros). Além disso, essa mobilidade ainda reproduz assimetrias em relação ao aprendizado e ao poder simbólico das línguas em contato (português e espanhol) no espaço escolar. Essas desigualdades de aprendizado das línguas estão associadas, por sua vez, às assimetrias geopolíticas e diferenças dos padrões de desenvolvimento entre as cidades, os estados/ províncias e os países vizinhos nessa região de tríplice fronteira.

Mas as escolas de fronteira também produzem barreiras. O funcionamento do PEIF durante esses anos tem gerado tensões efetivas advindas das formas de controle, planejamento das atividades pedagógicas, formação docente, descontinuidades políticas e financiamentos diferenciados dos Estados nacionais. Além disso, os sistemas educativos de cada país dividem o tempo (calendários anuais e horários) e o espaço das escolas (arquitetura dos edifícios, formas das salas de aula), assim como consolidam maneiras de pensar e classificar esse universo mediante suas legislações e formas de organização política e pedagógica.

Esse paradoxo talvez possa ser constitutivo das fronteiras em seus contextos de integração regional. Ver a experiência dessas escolas como processos simultâneos de integração e nacionalização possibilita problematizar tanto uma visão idealizada da integração (vista como uma união harmônica), como também uma visão pessimista, que geralmente contrasta as normativas idealizadas - em projetos, planos e documentos legais - com a falta de efetividade nas experiências concretas. Nosso caminho foi o de observar práticas sociais, contradições reais e tensões políticas e culturais que complexificam as fronteiras em seu campo de potencialidade, almejando relações interculturais questionadoras das relações assimétricas de poder (Walsh 2009; Oliveira e Candau 2010). 
Os enfoques teóricos do debate intercultural buscam pensar os dilemas contemporâneos diante da intensificação das demandas por reconhecimento e participação política de variados grupos - povos originários, diásporas africanas, redes migratórias, movimentos feministas, entre outros - presentes no interior dos Estados nacionais contemporâneos (Walsh 2009; Macagno 2014; Salvador Pech e Rizo García 2014). Entretanto, é relevante ampliar essa reflexão teórica para pensarmos também a singularidade das experiências interculturais que ocorrem nos territórios situados entre os Estados nacionais. Tais reflexões podem ser aprofundadas tanto por meio do estudo de políticas e práticas educacionais de integração transfronteiriça, como sobre os processos culturais e educacionais dos agentes locais que atuam nessas zonas de contato entre duas ou mais nações para além das políticas públicas de integração.

Uma perspectiva intercultural das escolas de fronteira deve evitar uma leitura que vincula automaticamente os conceitos de nação, território, cultura, identidade e língua. É importante perceber a complexidade e heterogeneidade da produção desses espaços culturais e educacionais entre duas localidades pertencentes a nações distintas. As escolas interculturais de fronteira, para além dos discursos oficiais, constituem-se em práticas sociais que possibilitam pensarmos as emergências culturais, as assimetrias nacionais, a insurgência das misturas de línguas e as diferenças étnicas. Essa realidade heterogênea, às vezes, embaralha os referentes nacionais, apaga as linhas precisas dos mapas e cria zonas imprecisas entre língua, cultura, identidade e território, como mostra a experiência narrada principalmente por professores e alunos da instituição educacional argentina e suas redes de relações transfronteiriças.

As escolas de fronteira são, portanto, espaços privilegiados para pensarmos as disjunções, as mesclas e aproximações capazes de problematizar o nacionalismo banal (Billig 1995) na produção cotidiana da nação no espaço escolar. Além disso, esse caminho de investigação possibilita questionar o nacionalismo metodológico presente em muitos de nossos procedimentos analíticos, uma vez que, em parte da tradição das ciências sociais, identificamos e reproduzimos algumas unidades de análise - sociedade, território, identidade, povo, etc. - como conceitos equivalentes ao Estado nacional (Wimmer e Glick-Schiller 2002; Schiller e Salazar 2013). 


\section{BIBLIOGRAFIA}

ALBUQUERQUE, José Lindomar C., 2015, "Procesos de fronterización y sentidos de pertenencia entre Brasil y Paraguay", em Alberto Hernandez e Amalia Campos-Delgado (orgs.), Líneas, Límites y Colindancias: Miradas a las Fronteras desde América Latina. Tijuana, Colegio de la Frontera Norte, 79-1 12.

AMARAL, Joana de Barros, 2016, "Apontamentos sobre políticas educacionais e as fronteiras brasileiras”, Revista Geopantanal, 21 : 23-38.

AMATO, Laura Janaina Dias, e Andrea Yulli RUIZ, 2017, "Patrimônio, língua e interculturalidade na escola pública: práticas e saberes", Interletras, 6 (25): 1-12.

ANDERSON, Benedict, 2008, Comunidades Imaginadas: Reflexões sobre a Origem e a Difusão do Nacionalismo. São Paulo, Companhia das Letras.

BALIBAR, Etienne, 2005, “¿Qué es una frontera?”, em E. Balibar, Violencias, Identidades y Civilidad: Para Una Cultura Política Global. Barcelona, Gedisa, 77-86.

BAUER, Otto, 2000, "Nação”, em Gopal Balakrishnan (org.), Um Mapa da Questão Nacional. Rio de Janeiro, Contraponto, 45-84.

BHABHA, Homi, 2003, O Local da Cultura. Belo Horizonte, UFMG.

BILlIG, Michael, 1995, Banal Nationalism. Londres, Sage Publications.

BILLIG, Michael, 1998, "El nacionalismo banal y la reproducción de la identidad nacional", Revista Mexicana de Sociología, 60 (1): 37-57.

CASTElls, Manuel, 2001, O Poder da Identidade, vol. II. São Paulo, Paz e Terra.

CRESSWELL, Tim, 2009, "Seis temas na produção das mobilidades", em Renato Miguel do Carmo e José Alberto Simões (orgs.), A Produção das Mobilidades: Redes, Espacialidades e Trajectos. Lisboa, Imprensa de Ciências Sociais, 25-40.

DELGADO, Amália Campos, e Olga Ordgers ORTIZ, 2012, "Crossing the border: mobility as a resource in the Tijuana/San Diego and Tecún Umán/Tapachula Regions”. Estudios Fronterizos, 13 (26): 9-32.

GRIMSON, Alejandro, 2003, La Nación en Sus Limites: Contrabandistas y Exiliados en la Frontera Argentina-Brasil. Barcelona, Gedisa.

HOLANDA, Sérgio Buarque de, 2000 [1959], "América portuguesa e Índias de Castela", em Sérgio Buarque de Holanda, Visão do Paraíso: Os Motivos Edénicos no Descobrimento e Colonização do Brasil. São Paulo, Brasiliense, 383-403.

MACAGNO, Lorenzo, 2014, O Dilema Multicultural. Curitiba, Graphia/Editora UFPR.

MECT/ME - Ministerio de Educación, Ciencia y Tecnología / Ministério da Educação, 2007, Programa Escuelas Bilingües de Frontera (PEBF): Modelo de Enseñanza Común en Escuelas de Zona de Frontera, a partir del Desarrollo de un Programa para la Educación Intercultural, con Énfasis en la Enseñanza del Portugués y el Español. Brasília e Buenos Aires, Ministério da Educação / Ministerio de Educación, Ciencia y Tecnología, disponível em < http://www .bnm.m e.gov.ar/giga 1/documentos/EL001427.pdf > (última consulta em outubro de 2019).

MOTA, Sara dos Santos, 2014, Portunhol e Sua Re-territorialização na/pela Escrit(ur)a Literária: Os Sentidos de Um Gesto Político. Santa Maria, RS, Universidade Federal de Santa Maria, tese de doutorado em Letras.

OLIVEIRA, Luis Fernandes de, e Vera Maria CANDAU, 2010, "Pedagogia decolonial e educação antirracista e intercultural no Brasil”, Educação em Revista, 26 (1): 15-40.

PEREIRA, Maria Ceres, 1999, Naquela Comunidade, os Adultos Falam "Brasileiro" e "Alemão", na Escola as Crianças Aprendem o "Português": Um Estudo do Continuum Oral/Escrito em 
Crianças de Uma Classe Bisseriada. Campinas, SP, Universidade Estadual de Campinas, tese de doutorado em Linguística Aplicada.

SALVADOR PECH, Cynthia, e Marta RIZO GARCÍA (coords.), 2014, Interculturalidad: Miradas Críticas. Bellaterra (Barcelona), Universitat Autònoma de Barcelona.

SCHILlER, Nina G., e Noel B. SALAZAR, 2013, "Regimes of mobility across the globe", Journal of Ethnic and Migration Studies, 39 (2): 183-200.

SMITH, Anthony, 2006, Nacionalismo. Lisboa, Teorema.

STURZA, Eliana Rosa, 2006, Línguas de Fronteira e Políticas de Línguas: Uma História das Ideias Linguísticas. Campinas, SP, Universidade Estadual de Campinas, tese de doutorado em Linguística.

STURZA, Eliana Rosa, 2014, "Introdução", número temático "Escolas Interculturais de Fronteira”, Salto para o Futuro, XXIV (1): 4-6.

Thomaz, Karina Mendes, e Ana Sheli T. ALTAMIRANDA, 2010, Diagnóstico Sociolinguístico: Foz do Iguaçu/Paraná - Brasil Puerto Iguazú/Misiones - Argentina. Florianópolis, IPOL.

TURNER, Victor, 2005, Floresta de Símbolos: Aspectos do Ritual Ndembu. Niterói, EdUFF.

WALSH, Catherine, 2009, Interculturalidad, Estado, Sociedad: Luchas (De)coloniales de Nuestra Época. Quito, Editorial Abya-Yala.

WIMMER, Andreas, e Nina GLICK-SCHILLER, 2002, "Methodological nationalism and beyond: nation-state building, migration and the social sciences", Global Network, 2 (4): 301-334. 